\title{
Against a reading of a sacred landscape: Raja Shehadeh rewrites the Palestinian presence in Palestinian Walks
}

In his introduction to Palestinian Walks, Raja Shehadeh remarks that in spite of the great number of travelers to Palestine, travel literature, for the most part, willfully ignored the living experience and existence of the land's inhabitants. Often, Palestine was the imaginary place that was continuously invented to confirm religious and political beliefs. The Biblical imagination, along with the orientalist gaze, informed the accounts, and anything that did not correspond to the preconceived repertoire was quickly discarded. The native inhabitants were the first victims. At best professed the savage other, they were not considered the land's rightful owners. Palestine was symbolically colonized in the Western imagination long before the British mandate. This vanishing homeland is a subject that dominates Shehadeh's nonfiction narrative. Accounts of his walks expose parts of his homeland's beauty and rewrite the Palestinian presence in its place, providing a counter-narrative to the Biblical imagination. 